URBANISMO NA ERA VARGAS: A TRANSFORMAÇÃO DAS CIDADES BRASILEIRAS.

Vera F. Rezende (org.).

Niterói: Editora da UFF; Intertexto, 2012.

\section{Fania Fridman}

Ao comemorar vinte anos, a Rede de Pesquisa Urbanismo no Brasil publicou uma coletânea de onze artigos de autoria de Vera Rezende; Sarah Feldman; Ana Fernandes; Maria Cristina da Silva Leme; José Francisco Bernardino Freitas; Marlice Soares de Azevedo; Célia Ferraz de Souza e Maria Soares de Almeida; Eneida Maria Souza Mendonça; Virginia Pontual e de Maria Lais Pereira da Silva que tratam da prática urbanística em capitais brasileiras nos dois primeiros governos de Getúlio Vargas (1930-1945). Além das singularidades dos projetos para as cidades examinadas em cada trabalho e dos valiosos dados empíricos, a riqueza desse livro também se revela ao suscitar importantes argumentos. Vejamos.

O período que se inicia com a Revolução de outubro de 1930 tendo à frente o Pai dos Pobres é associado à modernizaçáo conservadora e às intensas transformaçóes que sacudiram o país em diversos âmbitos. Foi época de radicalização política, precedida por movimentos e acontecimentos de vulto como o tenentismo, a organização do Partido Comunista, a Coluna Prestes e a Semana de Arte Moderna 1922. Questões externas também influenciaram as tomadas de decisão: para superar a crise do café decorrente da Grande Depressão de 1929, a principal meta foi deslocar o eixo dinâmico da economia do país por meio de políticas planejadas e orientadas para a industrialização e a diversificação da agricultura.

Com o nacionalismo como ideologia e o Estado acima dos conflitos sociais - a historiografia já consagrou a habilidade de Vargas em adiar conflitos e conciliar opostos -, a hegemonia da elite agráriomercantil ficou atenuada sem a imediata dominação dos interesses da burguesia industrial e financeira ou do proletariado urbano que se tornaram forças emergentes. Para o fortalecimento do capitalismo nacional consagrado pela Constituição de 1934, o
Estado interventor, mesmo sujeitando sindicatos, recebeu o apoio da classe trabalhadora mediante o estabelecimento da jornada de oito horas e do salário mínimo e a organização dos Institutos de Aposentadoria e Pensões (IAPs) de inúmeras categorias profissionais com a incorporação das Caixas de Aposentadoria e Pensóes. A burguesia urbana se fez presente nos Conselhos Técnicos (do Petróleo, de Águas e Energia, do Café, do Comércio Exterior, de Política Industrial e Comercial, de Economia e Finanças, de Mobilização Econômica e de Serviços Públicos com representantes da indústria, do comércio e de ministérios nomeados pelo presidente) e nos Conselhos Consultivos (cujos componentes eram indicados pelos interventores) instituídos em cada estado e no Distrito Federal. Estes possuíam competência para opinar e sugerir providências às autoridades municipais, estaduais e federais tal qual a supressão de impostos ou o estabelecimento ou extinção de municípios, entre outras medidas.

A administração pública desempenhou relevante papel enquanto agente da modernização e do controle da produção e do espaço mediante a criação de novos organismos - ministérios, autarquias, departamentos e institutos - e a promulgação de leis e códigos. Se é inquestionável a prioridade dada pela Revoluçáo de 1930 à integração do mercado nacional via reorganização econômica, este objetivo seria alcançado através da ampliação dos sistemas viário e urbano. $\mathrm{E}$ desde o início da década de 1930 são propostos tanto planos de remodelação das cidades brasileiras quanto programas territoriais constando de políticas de povoamento, de transporte e de comunicação. Nesse sentido, nos Anos Getúlio institucionalizaram-se no Brasil o urbanismo e o planejamento por intermédio da geração de uma burocracia técnica para atuar na estrutura governamental. Entenda-se que apesar ou em decorrência dos constrangimentos impostos pelos regimes liberal-democrático (1934-1937) e autoritário (Estado Novo), a legitimação desses campos profissionais pôde se dar pela separação das funções executivas das legislativas, ou seja, pelo afastamento da política das atividades de gestão. ${ }^{1}$

1 Enquanto alguns jornais noticiavam os "movimentos da modernidade" de Mussolini e de Hitler, durante o Estado Novo germanófilos e antisse- 
Desse modo, se a gestão pública neutra substituiu o conflito, o controle administrativo deve ser vinculado ao exercício político.

Os artigos da coletânea também evidenciam que desde a década de 1920 grupos de intelectuais, militares, eclesiásticos, empresários, trabalhadores e funcionários públicos pleiteavam ações nas cidades, antecipando as intervençóes físicas e as novas formas de gestão municipal empreendidas a partir de 1930. Contribuíram para a constituição do saber técnico e o enfrentamento dos problemas urbanos a abertura e/ ou reformulaçáo de cursos superiores para a formação de especialistas; a circulaçáo de livros e artigos acerca dos princípios e instrumentos do urbanismo europeu e norte-americano (como o zoneamento, a contribuição de melhoria e a expropriação marginal) e dos mecanismos institucionais que foram divulgados pelos docentes, consultores e quadros técnicos das prefeituras; as conferências pronunciadas por Le Corbusier e Alfred Agache; ${ }^{2}$ a realização de congressos e exposiçóes enquanto fóruns de veiculação de ideias; e a atuação da grande imprensa e de organizaçóes sociais e profissionais, entre as quais o Rotary Club, os Institutos Histórico e Geográfico, a Sociedade Amigos da Cidade de São Paulo, a Sociedade Amigos da Cidade do Rio de Janeiro, o Centro Carioca, o Centro Industrial do Brasil, o Instituto dos Arquitetos e o Clube de Engenharia, estimulando debates sobre as soluçóes para as mazelas urbanas. Foi aventada a suspeita de que essas organizaçóes ocuparam o espaço político deixado pelo fechamento das Câmaras Municipais durante o Estado Novo.

A Constituição de 1937 promoveu o município à qualidade de "órgão constitutivo dos poderes" justificando-se assim a criação de entidades, entre elas as Comissóes de Planos organizadas nos Departamentos das Municipalidades. ${ }^{3}$ Inspiradas

mitas ocuparam cargos no alto escalão do governo que, aliado à Igreja, definia os comunistas como "homens sem Deus". Cabe também relembrar o julgamento de mais de dez mil acusados após o Levante Comunista de 1935 e os assassinatos de motivação política.

2 Expressiva foi sua influência na posição de autor ou consultor de planos e projetos para o Rio de Janeiro, parque Farroupilha em Porto Alegre, Cidade Satélite da Pampulha em Belo Horizonte, Curitiba, bairro Interlagos em São Paulo, Petrópolis, Vitória, Cabo Frio, Araruama e São João da Barra. Agache ainda sugeriu uma Direção ou Repartição Permanente do Plano subordinada ao Executivo composta por pessoas com conhecimento da matéria urbana.

3 As Comissões do Plano das capitais e das maiores cidades brasileiras eram integradas pelos quadros administrativos; cidadãos notáveis vinculados a associações comerciais e profissionais; e por representantes da im- nas Comissóes norte-americanas, fizeram-se "espaços de legitimação do urbanismo, de adequação de práticas à realidade urbano-industrial, assim como de fortalecimento do município". E demonstraram a aceitação da ideia de plano - um conjunto de regras implantadas pelo serviço público para remodelação das cidades que cresciam com a industrialização, e não apenas de seus pedaços - entre governantes, elite burocrática, associaçôes civis e profissionais e a opiniáo pública. No entanto, apesar da sua composiçáo multidisciplinar e de suas subcomissóes (serviços públicos, finanças, gestão, zoneamento, museus-monumentos...), os planos permaneceram vinculados ao antigo ideário, privilegiando sobretudo as obras viárias, pouco incorporando os novos temas e problemas, expressando "a opçáo pelo urbanismo de projetos fracionados [...] e não por aquele constante da agenda urbanística em discussão, baseado em dados e levantamentos, embora contemplando intervençôes locais integradas".

Para a concentraçáo de poder no processo decisório do aparelho de Estado, foram instituídos outros canais, igualmente voltados para as políticas públicas. Os Departamentos Administrativos dos governos estaduais (ou Conselhos Administrativos, também chamados de Daspinhos, com membros indicados pelo presidente) eram órgáos de assistência técnica, jurídica e de fiscalização das finanças dos governos estadual e municipal. Substituindo as Assembleias Estaduais, hierarquizavam os interesses dos grupos políticos locais com a aprovação (ou não) dos orçamentos dos estados e municípios e opinavam sobre decretos a serem expedidos pelo interventor ou pelos prefeitos. Os Departamentos também definiram a vocação (industrial, estância hidromineral ou de centro turístico) de diversas cidades brasileiras, acompanharam os projetos de edificaçóes, a implantação de obras públicas e elaboraram planos de urbanização e regulamentos.

Do mesmo modo que as transformaçóes políticas, econômicas e institucionais, as Comissóes, Conselhos Técnicos e Departamentos evidenciam a centralidade atribuída aos espaços urbanos. No livro, foi

prensa, do Rotary Club, da Sociedade Brasileira de Turismo (Touring Club do Brasil) e do Automóvel Club. Nas cidades do interior seu papel foi exercido por instituições externas ao corpo municipal. Assinale-se também que os Departamentos de Organização Administrativa existiam em São Paulo, Rio de Janeiro e Minas Gerais ainda na primeira metade de 1930. 
levantada a hipótese que na Era Vargas delineou-se a política nacional para as cidades quando o governo incorporou a questáo urbana, seja pela pressão popular, seja por necessidade de estabelecimento das melhorias exigidas pela industrialização. Essa política vinculava-se ao sistema técnico de administração, à legislação, à habitação, ao conhecimento do território, à criação de novas cidades e aos planos diretores. "É nesse sentido, portanto, que nos parece ser possível trabalhar, para o período em tela, com a ampliação da ideia de planejamento como função de governo", sendo a cidade o objeto estratégico de atuaçáo e o urbanismo uma prática em prol do interesse público, paradoxalmente ancorada na despolitização e tecnificação da atuação profissional buscando formas de conciliação entre o capital e o trabalho.

Quanto à legislação, pela Constituição de 1934 a propriedade do solo ficou dissociada do subsolo, agora concedida e controlada pelo poder federal. Assinalem-se ainda o artigo 113 (item 17), dando função social à propriedade, e o artigo 124, relativo à cobrança da contribuição de melhoria sobre a valorização do imóvel urbano originada pelas obras públicas, autorizando o governo a ingerir-se no direito de propriedade submetendo-a ao interesse coletivo. Ainda que esses dois artigos tenham sido prescritos pela Constituição de 1937, neste mesmo ano foram promulgados preceitos jurídicos relativos aos loteamentos e, posteriormente, normas sobre desapropriação por utilidade pública pelos municípios, estados e territórios. ${ }^{4} \mathrm{E}$ quando a atividade imobiliária já se consolidara em aplicação segura garantindo uma renda aos proprietários, a Lei do Inquilinato congelou os aluguéis.

Nessa política nacional para as cidades, ocorreu uma significativa mudança no trato da moradia operária que, inserida na agenda governamental, orientou-se pela ação dos IAPs e de iniciativas locais. Tomando-se o exemplo paradigmático do Código de Obras do Rio de Janeiro (Decreto ${ }^{\circ} 6.000$ de 1937), verifica-se que visando "o ordenamento racional da cidade" delimitou os locais para as habitações proletárias e determinou a extinção das favelas e cortiços com a transferência das famílias para unidades habitacionais salubres. À espera da

4 Os territórios federais do Amapá, Rio Branco, Guaporé, Iguaçu e Ponta Porã foram instaurados em 1943. conclusão de tais unidades, milhares de pessoas foram deslocadas para os Parques Proletários Provisórios, logo transformados em permanentes. Por outro lado, praticamente um quarto das novas moradias aprovadas pela Prefeitura foram erigidas pelos IAPs nos subúrbios. Para inúmeras cidades constata-se ainda que no período Vargas não foram poucos os decretos proibindo favelas e os planos urbanísticos que propuseram a construção de bairros operários em locais afastados servidos pelas linhas férreas. Nesse sentido, admite-se que a produção da casa dos pobres sendo alvo da intervenção do Estado deslocou o problema da "forma" da habitação para o "espaço", ou seja, de "questão social" converteu-se em "questáo urbanística".

As intervençôes sugeridas pelos planos e implantadas nas urbs brasileiras - a modernização das áreas centrais e seus arredores mais valorizados, a expulsão da população trabalhadora para os afastados bairros populares onde se localizariam as indústrias e a criação de melhores condições para a nova economia - tiveram como efeito a formação de periferias empobrecidas. Expandindo o espaço, durante os anos 1940 nos maiores núcleos delinearam-se metrópoles que exigiram a mudança dos pressupostos da intervenção: de urbanismo para planejamento (incluindo as regióes) nas operaçóes "cúmplices do desenvolvimento desejado".

Em relação ao território, base de afirmação da nova sociedade e do sentimento de nacionalidade, este precisava ser conhecido e administrado. Com esse objetivo, o Instituto Nacional de Estatística (1934) e o Conselho Nacional de Geografia $(1937)^{5}$ foram anexados em 1938 ao Instituto Brasileiro de Geografia e Estatística. Seu primeiro projeto, conhecido como Lei Geográfica do Estado Novo ou Campanha dos Mapas Municipais, foi determinar as coordenadas das cidades e vilas brasileiras. Sendo de competência da União a definição dos limites do território nacional e o recenseamento da população, coube aos interventores solicitar aos prefeitos a definição do quadro urbano e suburbano tanto dos núcleos quanto das vilas dos distritos de cada

5 No Conselho Nacional de Geografia discutiam-se, com a presença de intelectuais, militares e de funcionários, questões relativas à integração territorial, colonização agrícola e à localização da nova capital no sentido de subsidiar decisões do governo. 
município, relação que deveria vir acompanhada por uma planta. Servindo para o controle e a ocupação, todas as sedes municipais com pelo menos 200 moradias tornaram-se cidades de acordo com o Decreto-Lei Federal n 311 de 1938, e vários programas idealizaram novos assentamentos urbanos vinculados a projetos industriais e/ou de colonização localizados em regiôes vazias no interior do país.

Outras instituiçôes foram criadas em 1937: o Serviço de Patrimônio Histórico e Artístico Nacional, oferecendo uma nova perspectiva para o urbanismo ao aderir às propostas modernistas e à preservação de objetos artísticos e de edificações consideradas representativas arquitetônica e culturalmente das raízes brasileiras; e o Departamento Nacional de Estradas e Rodagens, para integrar o país promovendo planos e os meios de comunicação entre as regiōes e a rede urbana. ${ }^{6}$

Primazia dos interventores, o "plano urbanístico da Era Vargas" para as capitais previu obras viárias para a melhoria da circulação entre os bairros e em direção ao centro com a abertura de avenidas e o alargamento de ruas, cuja referência em muitos casos teria sido o Plano de Avenidas para São Paulo (publicado em 1930), um sistema radial-perimetral aliado a princípios de zoneamento e a instrumentos normativos e de financiamento. A política abrangente de remodelação urbana que também sofreu influência estética trazida pelo

6 A Inspetoria dos Monumentos Históricos havia sido organizada em 1934, dando origem às inspetorias estaduais em Pernambuco, Bahia e Minas Gerais. Naquele mesmo ano foi publicado um Plano Geral de Viação Nacional cuja prioridade estava na integração da rede ferroviária com a navegação fluvial. O 10 Plano Rodoviário Nacional do DNER foi aprovado somente em 1944. movimento moderno, priorizou a reconstrução e a expansão da área central, o zoneamento com a setorização das atividades, novos índices urbanísticos e códigos edificatórios, o sistema de parques e jardins, novos bairros residenciais para as classes média e alta, a instalação de zona industrial, dos bairros operários e de obras de infraestrutura e equipamentos ${ }^{7}$ que revertessem em favor do desenvolvimento das economias tradicional e industrial e da nova ordem social.

Se "a modernidade e o autoritarismo foram dois movimentos que fizeram parte do mesmo processo", a intenção do urbanismo para esta "cidade moderna do autoritarismo" foi a de criar uma nova imagem, torná-la vitrine e instrumento de propaganda do governo Vargas que favorecesse o sentimento de unidade. Os decretos de desapropriaçóes e a derrubada de quadras deram origem a avenidas remodeladas e grandiosas, cenário dos desfiles da juventude e de paradas militares "quando se comemorava a exaltação à pátria”.

São estas, entre tantas dignas de nota, as contribuições trazidas nesse livro. Se o Tempo Getúlio vem sendo revisitado e despertando interesse de autores de diversos campos disciplinares, o "Urbanismo na Era Vargas: a transformação das cidades brasileiras" constitui-se em obra de referência obrigatória. As pesquisas ali publicadas ajudam a decifrar o urbanismo e o planejamento urbano daquele período que, anos depois, teriam longa carreira entre nós.

7 Que podiam incluir o aterro de mangues, o desmonte de morros (semelhante ao que ocorrera com o morro do Castelo carioca), a urbanização de encostas, a ampliação da área portuária, as edificações para o ensino, a religião e a saúde quanto à pavimentação e iluminação nos subúrbios. 